\title{
Lessons Learned: How to Organize Your Laboratory Meetings
}

In this issue, JAB continues a series of editorials from highly impactful faculty and researchers on "lessons learned" throughout their careers or lives. The hope is that the rest of us can benefit from their experiences. I would like to thank these individuals for sharing their thoughts with us.

-Michael Madigan, Editor-in-Chief

Nicholas Stergiou (nstergiou@unomaha.edu) is with the Division of Biomechanics and Research Development, University of $\mathrm{Ne}$ braska Omaha, Omaha, NE; and the College of Public Health, University of Nebraska Medical Center, Omaha, NE.

I was asked by the Editor-in-Chief to provide advice or guidance or "lessons learned" that contributed to my individual success professionally. Interestingly, I just finished a book on this topic called Advice for the Novice Investigator: Examples Taken From Movement Sciences that was published by CRC Press in August of 2019. The book is available at https://www.crcpress. com/Advice-for-the-Novice-Investigator-Examples-Taken-fromMovement-Sciences/Stergiou/p/book/9781138626188. The publishers were kind enough to allow me to use a piece from the book for this editorial. I decided to present the type of meetings I used to run my laboratory.

I have a list of activities that I have followed ever since I started my academic career in order to be an effective manager and head. Probably, the most important is my organized scheme of meetings.

Individual Meetings: I utilize individual meetings every week. These are meetings with my staff and the members of my research team. These are usually short, around 15 minutes, and based on the weekly reports. The main goal of these meetings is to address items of immediate concern and to answer any immediate questions.

Team Meetings: I meet with my research team (undergraduate and graduate students, research associates, etc) every other week. This is called a team meeting and lasts 60 minutes. One of the students is responsible to prepare the agenda and to type the minutes as we discuss everything. We go over all the projects without discussing findings, mostly just business-related items. We address issues related to data collections, data analysis, informed consents, equipment, recruiting, and so on. We also go over all the manuscripts and grants we have active, pending, or in progress. Finally, we discuss submission of abstracts and presentations in conferences.

Data Meetings: The in-between weeks when I do not have team meetings, I organize data meetings that last for 60 to 90 minutes. During these meetings, my research team discusses results from the different projects we have in progress, ideas, grant submissions, and so on. The format is slide-based presentations where exchange of ideas and feedback is emphasized.

Journal Clubs: For the team and data meetings, I usually target Mondays. However, for the Journal Club, I target Fridays or another day toward the end of the week. It lasts 60 minutes. My entire research team participates, and the goal is to discuss 3 to 4 scientific papers that we have read. I require the participants to have critically analyzed the papers. I do not expect anyone to present the papers as we move directly into its critique. Questions such as "what you like and don't like" in this paper are usually the first posed. I emphasize critical thinking and discussion. Many times, I give assignments such as digging deeper in the literature with respect to a specific topic. I usually identify the scientific papers that we are going to read. However, I also encourage team members to step forward to identify papers that they would like everyone to read.

For journal clubs, many times I ask my team to meet outside the university (a coffee shop, a diner, or even a pub). The goal is to promote a sense of being away from a classroom and to encourage participants to express opinions more freely. The majority of my doctoral students and research associates consider our journal clubs the most important educational experience of their time with me. One of them placed a coffee mug from the place where we used to meet on the first page of his dissertation. Another mentioned it in her acknowledgments. Therefore, I strongly encourage having journal clubs and pay particular attention in the selection of the papers to be discussed.

Nicholas Stergiou

University of Nebraska at Omaha

\section{Acknowledgment}

Grant funding to support this work was received from National Institutes of Health (NIGMS/P20GM109090). 